\title{
A Comparison of Adsorption Equilibrium, Kinetics and Thermodynamics of Aqueous Phase Clomazone between Faujasite $X$ and a Natural Zeolite from Kenya
}

\author{
Victor O. Shikuku, ${ }^{a, b}$, Filipe F. Donato ${ }^{b}$, Chrispin O. Kowenje, \\ Renato Zanella ${ }^{\mathrm{b}}$ and Osmar D. Prestes ${ }^{\mathrm{b}}$ \\ ${ }^{a}$ Maseno University, P.O. Box 333-40105, Maseno, Kenya. \\ ${ }^{b}$ Laboratory of Pesticide Residue Analysis (LARP), Chemistry Department, Federal University of Santa Maria, \\ 97105-900 Santa Maria-RS, Brazil.
}

Received 6 June 2015, revised 8 October 2015, accepted 14 October 2015

\begin{abstract}
In this study, a well-studied synthetic faujasite $\mathrm{X}$ (FAU-X) zeolite and a recently discovered natural zeolite material from Kenya (NZ-K) were compared for their efficiency in removal of clomazone, a herbicide and water contaminant, from aqueous solution. The adsorption kinetics, isotherms and thermodynamics parameters were investigated. Equilibrium sorption data were describable by both the Langmuir and Freundlich models. The adsorption kinetics obeyed the pseudo-second-order kinetic law while pore diffusion was not the sole operating rate determining step. The derived thermodynamic parameters, namely $\Delta \mathrm{G}$ and $\Delta \mathbf{H}$, indicated the adsorption process was feasible, spontaneous and exothermic for the natural zeolite and non-spontaneous for the synthetic zeolite via a physical and chemical process, respectively. The natural zeolite proved to be a suitable low-cost adsorbent for clomazone removal with removal efficiency above $70 \%$, five-fold more efficient than faujasite $\mathrm{X}$.
\end{abstract}

KEYWORDS

Adsorption, natural zeolite, faujasite $\mathrm{X}$, clomazone.

\section{Introduction}

Clomazone, (2-[(2-chlorophenyl)methyl]-4,4-di- methyl-3-isoxazolidinone), Fig. 1, is a widely used herbicide to control annual broadleaf weeds in the cultivation of rice, sugar cane and diversity of vegetable crops ${ }^{1}$. Environmentally, clomazone has been frequently detected in ground and surface waters as a persistent pollutant hence water contamination by clomazone is of great environmental concern ${ }^{1,2}$. In addition, exposure to clomazone has been proven to be detrimental to both land and aquatic lives ${ }^{3,4}$. Since conventional wastewater treatment technology that employs a sequence of both adsorption process onto adsorbents such as activated carbon and biological treatment such as active sludge method has been demonstrated to be insufficient for removal of most organic micropollutants ${ }^{5}$, alternative strategies for pesticides removal are still needed. Photocatalysis using $\mathrm{TiO}_{2}$, so far proves to be an especially efficacious method for denaturing clomazone in water ${ }^{6}$. However, photodegradation always result in formation of intermediates that can be environmentally hazardous as the parent molecule ${ }^{7}$; hence other environmentally friendly and low-cost alternatives that would eliminate both the pesticides and their breakdown products still need to be evaluated. Recently, zeolites have found applications in environmental remediation. Zeolites are crystalline aluminosilicate minerals with specific microporous structures of cavities and pore dimensions with physicochemical characteristics such as sorption, cation exchange molecular sieving and catalysis ${ }^{8,9,10}$. Unlike their synthetic counterparts, natural zeolites which commonly occur in volcanic active areas are highly varied in chemical composition ${ }^{11}$. Both synthetic and natural zeolites have widely been separately used as adsorbents and molecular sieves for pesticide remediation from wastewaters ${ }^{8,9,10}$. Several workers

* To whom correspondence should be addressed. E-mail: ckowenje@maseno.ac.ke / kowenje@yahoo.com

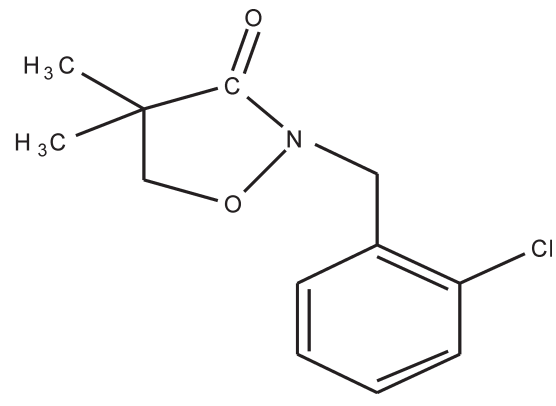

Figure 1 Structure of clomazone.

have reported the differences between the two types of zeolites. Specifically, in analyzing South African natural zeolites which had similar properties as that of NZ-K in this study, Diale et al. ${ }^{11}$ found that the BET surface area ranged from 65.5 to $33.22 \mathrm{~m}^{2} \mathrm{~g}^{-1}$ while the pore size ranged from 3 to $10 \mathrm{~nm}$ and pore diameters of 10 to $18 \mathrm{~nm}$ for the natural zeolites. Total cation exchange ranged between 0.37 and $0.41\left(\mathrm{meq} \mathrm{g}^{-1}\right)$. In contrast, the $\mathrm{NaX}$ has a specific surface area of $360-451\left(\mathrm{~m}^{2} \mathrm{~g}^{-1}\right)$ and pore volume of $0.226-0.33\left(\mathrm{~cm}^{3} \mathrm{~g}^{-1}\right)$ while the pore diameters are between 2 and $8 \mathrm{~nm}$. In this work, the adsorption kinetics and thermodynamics of synthetic faujasite X (FAU-X) and a natural zeolite from Kenya (NZ-K) for removal of clomazone from water are for the first time, reported.

\section{Materials and Methods}

\subsection{Procedure}

\subsubsection{Preparation of Adsorbent}

The Faujasite $X(\mathrm{Si} / \mathrm{Al}=1.5$ and $0.2 \mu \mathrm{m}$ in particle size $)$ which was obtained from Sigma-Aldrich Chemical company, (St Louis, 
MO, USA) was first activated under $200 \mathrm{mmHg}$ vacuum. The preparation procedure was as described in our previous work'. For activation, $50 \mathrm{~g}$ of FAU-X was weighed in a flask that was then evacuated for $30 \mathrm{~min}$ at room temperature. The contents were then heated at $343 \mathrm{~K}$ and continuous heating was done by raising the temperature by $30 \mathrm{~K}$ every $30 \mathrm{~min}$ up to $403 \mathrm{~K}$. Finally, the temperature was then raised to $423 \mathrm{~K}$ and heating maintained for $105 \mathrm{~min}$. The flask was allowed to cool at room temperature and the contents transferred to a sealed glass bottle for later use.

The NZ-K was obtained from near Naivasha city $\left(36.50^{\circ} \mathrm{E}\right.$, $0.90^{\circ} \mathrm{S}$ ) in Kenya. The material was chunky and was then crushed and homogenized for the adsorption experiments. The material was sieved through $1 \mathrm{~mm}$ sieve for uniform particle size. The sorbent was then washed thrice in ultrapure water to remove impurities. Finally, the material was activated under similar protocol to that of FAU-X above.

\subsubsection{Sorption Kinetics}

For purposes of comparison, the adsorption kinetics experiments were performed under batch mode separately for FAU-X and NZ-K zeolites ${ }^{12}$. Here, a mass of $0.1 \mathrm{~g}$ of each adsorbent was independently, in triplicate, dispersed into $50 \mathrm{~mL}$ of $500 \mu \mathrm{g} \mathrm{L}^{-1}$ of clomazone at $293 \mathrm{~K}$ and stirred at $300 \mathrm{rpm}$ for $6 \mathrm{~h}$. At predetermined intervals $(0.25,0.5,1,2,3,4,5,6 \mathrm{~h})$ residual pesticide in solution was analyzed. Clomazone was detected by HPLC-DAD at $212 \mathrm{~nm}$. The mobile phase was a mixture of acetonitrile (obtained from Mallinckrodt, NJ, USA) and water $(60: 40 \mathrm{v} / \mathrm{v})$ adjusted to $\mathrm{pH} 3$ using phosphoric acid supplied by Merck (Brazil) $(1: 1 \mathrm{v} / \mathrm{v})$, with a flow rate of $0.8 \mathrm{~mL} \mathrm{~min}^{-1}$. The injection volume was $20 \mu \mathrm{L}^{1}$. The amount adsorbed at time $t$, was obtained by the mass balance equation:

$$
q_{t}=\frac{\left(c_{0}-c_{t}\right)}{m} V
$$

To generate the kinetics parameters, the kinetic data were then fitted to the pseudo-first-order ${ }^{13}$, pseudo-second-order ${ }^{14}$ and intraparticle diffusion ${ }^{15}$ equations below. The equations can be expressed as:

$$
\begin{aligned}
& \text { Pseudo-first-order model: } \log \left(q_{e}-q_{t}\right)=\log q_{e}-\frac{k_{1}}{2.303} t \\
& \text { Pseudo-second-order model: } \frac{t}{q_{t}}=\frac{1}{k_{2} q_{e}^{2}}+\frac{t}{q_{e}} \\
& \text { Intraparticle diffusion: } q_{t}=k_{p} t^{0.5}+C
\end{aligned}
$$

\subsubsection{Adsorption Isotherm Studies}

In obtaining the adsorption isotherm parameters, $0.1 \mathrm{~g}$ of the adsorbent materials were individually, in triplicate vessels, dispersed into Erlenmeyer flasks containing $50 \mathrm{~mL}$ of various separate doses of clomazone (100-1000 $\left.\mu \mathrm{g} \mathrm{L}^{-1}\right)$ and magnetically stirred at $300 \mathrm{rpm}$ and $293 \mathrm{~K}$. After equilibration, the solutions were decanted and the supernatant filtered through $0.2 \mu \mathrm{m}$ filters for residual clomazone analysis as above. The per cent adsorbed (\%) was obtained by:

$$
\% \text { adsorbed }=\frac{C_{0}-C_{e}}{C_{0}} \times 100
$$

The equilibrium adsorption capacity, $q_{e}$, at different adsorbate concentration levels was obtained by the equation:

$$
q_{e}=\frac{V\left(C_{0}-C_{e}\right)}{m}
$$

Three adsorption isotherm equations, namely Langmuir ${ }^{16}$, Freundlich ${ }^{17}$ and Temkin ${ }^{18}$ were applied to fit the experimental data. The linear forms of these equations are given by:
Langmuir isotherm: $\frac{1}{q_{e}}=\frac{1}{Q_{0}}+\frac{1}{Q_{0} K_{L} C_{e}}$

Freundlich isotherm: $\log q_{e}=\log K_{f}+\frac{1}{n} \log C_{e}$

Temkin isotherm: $q_{e}=\frac{R T}{b_{T}} \ln A_{T}+\frac{R T}{b_{T}} \ln C_{e}$

\subsubsection{Thermodynamic Studies}

The method by Moussavi et al. ${ }^{19}$ was adopted. Here, too, $0.1 \mathrm{~g}$ of adsorbents was separately dispersed into $50 \mathrm{~mL}$ of $500 \mu \mathrm{g} \mathrm{L}^{-1}$ of clomazone and stirred at $300 \mathrm{rpm}$ at 293, 303, 313 and $323 \mathrm{~K}$, also in triplicate. After equilibration, $1.0 \mathrm{~mL}$ aliquots were withdrawn from the flask and transferred into sealed glass vials for residual pesticide analysis as above.

\subsubsection{Instrumentation}

For instrumentation, water purifier Milli-Q system UV3 Direct (18.2 $\mathrm{M} \Omega \mathrm{cm}$ resistivity) from Millipore (Bedford, MA, USA), analytical balance accurate model APX 200 (Denver Instrument, USA), Ultrasound bath Bandelin Sonorex RK 510 (Walldorf, Germany), Vacuum Pump Tecnal TE-058 (Piracicaba, SP, Brazil), Liquid Chromatograph Varian (Palo Alto, CA, USA), equipped with pump model 210, diode array detector (DAD) Pro Star 335, data acquisition system Star Workstation 6.0, analytical column Gemini $5 \mu \mathrm{C} 18(250 \times 4.6 \mathrm{~mm}$ id; $5 \mu \mathrm{m})$ and guard column $(20 \times$ $1 \mathrm{~mm}$ ) of the same material, both containing octadecylsilanemodified silica (Phenomenex, Torrance, CA, USA), X-ray Brucker diffractometer (D8 Advance) with copper radiation $(K \alpha=1.5406)$ and Perkin Elmer (400 FT-IR spectrometer) with ATR (attenuated total reflection) attached were used.

\section{Results and Discussion}

\subsection{Characterization of the Zeolite}

The zeolites were characterized by X-ray diffraction and FT-IR. The XRD instrument settings were $40 \mathrm{KV}, 30 \mathrm{~mA}$, step size of $0.02^{\circ}$ $(2 \theta)$ and a scan rate of $2 \theta \mathrm{min}^{-1}$ for $5^{\circ} \leq(2 \theta) \leq 50^{\circ}$. The chemical composition and vibrational identity of NZ-K is shown in Table 1 and Fig. 3, respectively. The NZ-K contained several cations, including $\mathrm{Ca}^{2+}, \mathrm{Mg}^{2+}, \mathrm{Na}^{+}, \mathrm{K}^{+}, \mathrm{Mn}^{2+}$ and $\mathrm{Fe}^{3+}$ in decreasing order by weight (Table 1). Also, the ratio of $\mathrm{SiO}_{2}$ to $\mathrm{Al}_{2} \mathrm{O}_{3}$ was around 5 .

Comparing the XRD peak intensities (Fig. 2) pattern of NZ-K with that of standard clinoptilolite, the natural zeolite (NZ-K) from Kenya is likely to be majorly composed of Clinoptilolite $^{20,21,22}$. Clinoptilolite is one of the most common and abundant naturally occurring zeolites ${ }^{22}$. The FT-IR spectrum in Fig. 3 was also used in characterizing the NZ-K. The frequency peak at 3500 (Fig. 3) was attributed to $\mathrm{OH}$ group indicating hydration by water molecules associated with cations in the cages and channels of the zeolite framework. The band centred at $1000 \mathrm{~cm}^{-1}$ refers to asymmetric stretching vibration modes of internal T-O bonds in $\mathrm{TO}_{4}$ tetrahedra $(\mathrm{T}=\mathrm{Si}$ and $\mathrm{Al})$ while the band near $800 \mathrm{~cm}^{-1}$ and that proximal to $500 \mathrm{~cm}^{-1}$ were assigned to the stretching vibration modes of $\mathrm{O}-\mathrm{T}-\mathrm{O}$ groups and the bending

Table 1 Chemical composition (wt \%).

\begin{tabular}{lr}
$\mathrm{SiO}_{2}$ & $62.2 \%$ \\
$\mathrm{Al}_{2} \mathrm{O}_{3}$ & $13.3 \%$ \\
$\mathrm{CaO}$ & $12.00 \%$ \\
$\mathrm{MgO}$ & $1.64 \%$ \\
$\mathrm{Na}$ & $3.09 \%$ \\
$\mathrm{~K}_{2} \mathrm{O}$ & $0.17 \%$ \\
$\mathrm{MnO}$ & $0.20 \%$ \\
$\mathrm{Fe}_{2} \mathrm{O}_{3}$ & $4.83 \%$ \\
\hline
\end{tabular}




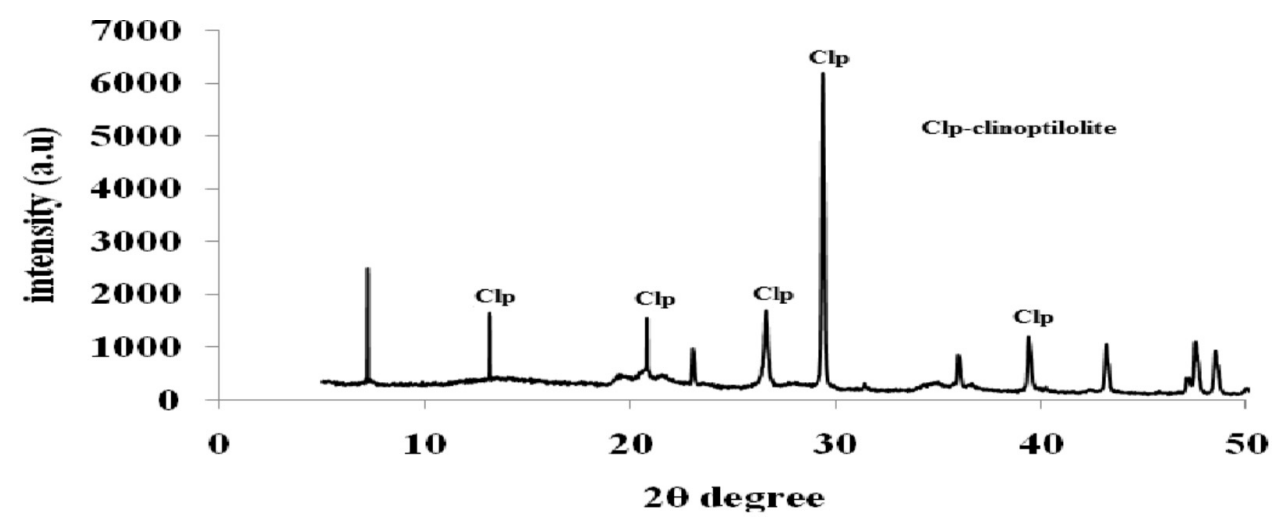

Figure 2 X-ray diffractogram of NZ-K (duplicate).

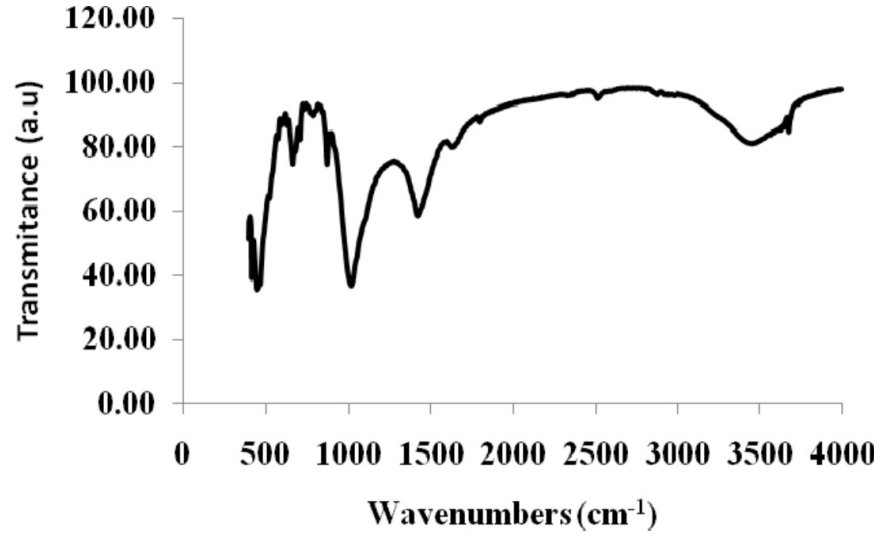

Figure 3 FT-IR spectrum from $450-4000 \mathrm{~cm}^{-1}$ for the NZ-K (duplicate).

vibrations of $\mathrm{T}-\mathrm{O}$ bonds, respectively. These are typical clinoptilolite vibration bands and are consistent with results by Mansouri et al..$^{22}$.

\subsection{Adsorption Kinetics}

The $\mathrm{pH}$ values of all the solutions were found to be in the range of 8.0-9.0 for all tests. The amount of clomazone uptaken by both zeolites increased rapidly within $1 \mathrm{~h}$ followed by a slower phase up to the second hour when maximum adsorption was reported after which it levelled-off indicating pseudo-equilibrium was achieved (Fig. 4a). The initial faster uptake of the pesticide is attributed to the large number of vacant binding sites at the beginning. In this regard, the capacity of NZ-K is unexpectedly determined to be about four times higher than that of FAU-X while both indicated a pseudo-equilibrium time of $2 \mathrm{~h}$. Conventionally, the sodium-type FAU-X (Na-X; because it is $\mathrm{Na}^{+}$ions exchanged zeolite $X)$ with larger surface area ${ }^{11}$ is expected to possess higher uptake rates. However, the higher rates posted by the NZ-K relative to FAU-X is a phenomenon hitherto unexplained but may partly be attributed to the presence of different exchangeable cations (Table 1) that would act variously and possibly synergistically with the pesticide. Each exchanged cation would offer specific surface chemical properties in the wider pore diameter of NZ-K hence plays dominant role over surface area effects ${ }^{23}$. Such different cations are expected to offer varied attractive surface energies to the adsorbent. Moreover, the rapidity of adsorption rates are desirable characteristics for any adsorbent for wastewater purification regimes. Earlier, Alver and Metin ${ }^{12}$ had made a similar observation in their study of anionic dye removal using modified zeolites where equilibrium was established within $2 \mathrm{~h}$.

The kinetic data were fitted for both pseudo-first-order and pseudo-second-order kinetics. A large correlation coefficient $\left(R^{2}>0.99\right)$ depicted that the adsorption of clomazone onto both zeolite materials followed pseudo-second-order kinetics (Fig. 4b). The second-order kinetics, in this case, is therefore consistent with both the number of adsorption sites and the number of pesticide molecules participating in the rate determining step.

Additional kinetic parameters of the initial adsorption rate

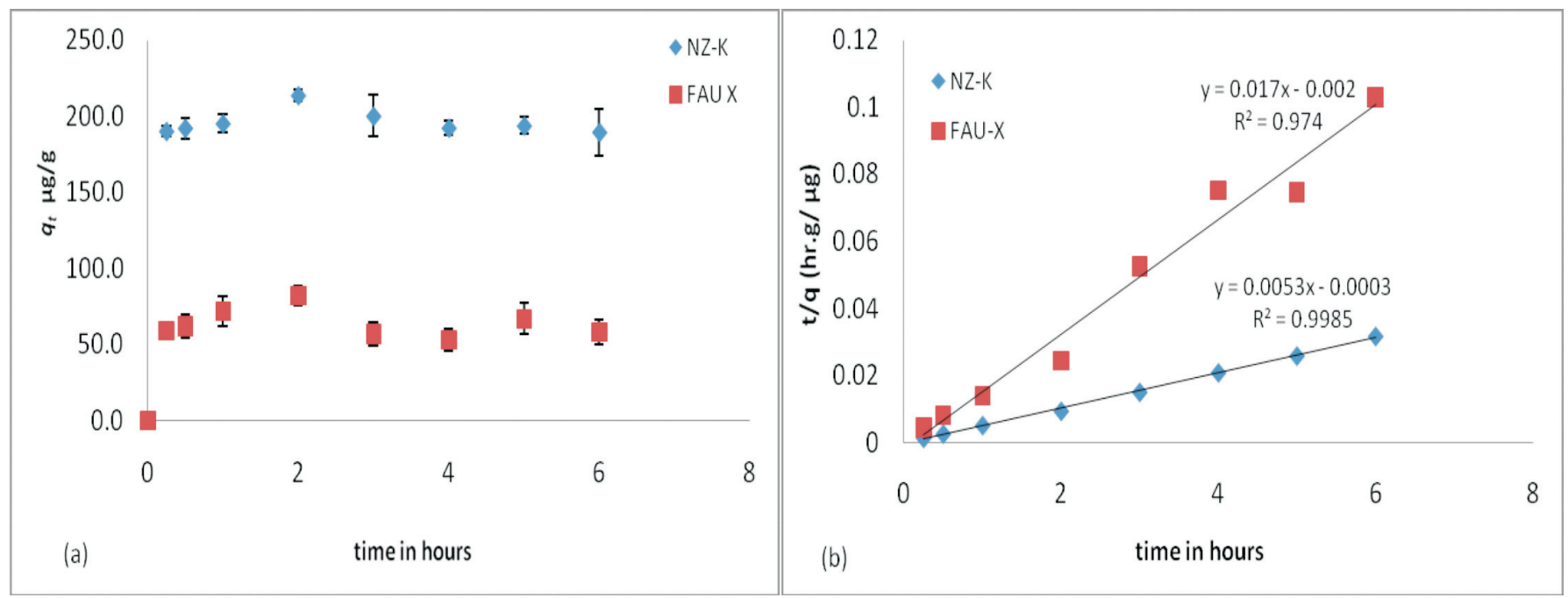

Figure 4 (a) Variation of clomazone amount adsorbed with contact time (triplicate). (b) Pseudo-second-order kinetics model for clomazone adsorption on FAU-X and NZ-K (triplicate). 
$\left(S_{\text {rate }}\right)$ and adsorption half-life $\left(t_{0.5}\right)$ were obtained from the regression plot using Eqs. 10 and 11, respectively ${ }^{24}$. The results are included in Table 2 .

$$
\begin{aligned}
& S_{\text {rate }}=k_{2} q_{e}^{2} \\
& t_{1 / 2}=\frac{1}{k_{2} q_{e}}
\end{aligned}
$$

The half-life $\left(t_{0.5}\right)$ of sorption process of 0.1177 and 0.0566 for FAU-X and NZ-K, respectively (Table 2), indicate a faster adsorption rate of clomazone onto the NZ-K than the FAU-X zeolite. The observed faster rate of adsorption is expected as it is consistent with high adsorption capacity for NZ-K depicted in Fig. 4a.

The migration mechanism of the adsorbate from the bulk solution to the adsorbent surface is documented to occur in several steps and the rate may be controlled by one or more steps such as; external surface diffusion, pore diffusion and adsorption on the pore surface.

To quantify the process, the kinetic data were fitted to intraparticle diffusion model (Eq. 4) in order to investigate the adsorption mechanism and the rate controlling step. From the model, when the regression of $q_{t}$ versus $t^{0.5}$ is multi-linear, then two or more processes influence the sorption behaviour ${ }^{25}$. However, when the line passes through the origin, then intraparticle diffusion is the only rate-limiting step. Clomazone was adsorbed in two (I and II) main phases (Fig. 5). The initial instantaneous adsorption (phase I) was attributed to external surface adsorption followed by a slow increase in adsorption tending to maxi-
Table 2 Pseudo-second-order kinetic parameters for removal of clomazone.

\begin{tabular}{lccc} 
Adsorbent & $\begin{array}{c}\text { Initial sorption rate } \\
/ \mu \mathrm{g} \mathrm{min}^{-1}\end{array}$ & $\begin{array}{c}\text { Adsorption half-life } \\
/ \mathrm{h}\end{array}$ & $\begin{array}{c}\text { Calculated } R^{2} \\
/ \mathrm{a} . \mathrm{u}\end{array}$ \\
\hline FAU-X & 8.33 & 0.1177 & 0.97 \\
NZ-K & 55.56 & 0.0566 & 0.99 \\
\hline
\end{tabular}

mum adsorption value at $2 \mathrm{~h}$ attributed to possible pore diffusion and heterogeneity of the adsorbent surfaces and the attempt of the pesticide molecules to reptate into the smaller zeolitic channels, pores and cavities ${ }^{26}$. Finally the last phase (II) is indicative of complete coverage of the active binding sites and subsequent desorption due to agitation, implying a pseudoequilibrium conditions. The attainment of the pseudo-equilibrium situation is observable in Fig. 4a as well. Finally, the plot did not pass through the origin. This is consistent with the pore diffusion not being the only rate-controlling step, but other rate controlling processes may be involved ${ }^{27,28}$.

\subsection{Adsorption Isotherm Modelling}

When the initial clomazone concentration was increased from 100 to $1000 \mu \mathrm{g} \mathrm{L}^{-1}$, the equilibrium adsorption capacity linearly increased from 19.1 to $178.3 \mu \mathrm{g} \mathrm{g}^{-1}$ (Fig. 6) for natural zeolite and from 4 to $63 \mu \mathrm{g} \mathrm{g}^{-1}$ for synthetic FAU-X. According to Jalil and co-workers ${ }^{29}$, the observation is consistent with mass transfer functioning as the driving force for the transport of clomazone

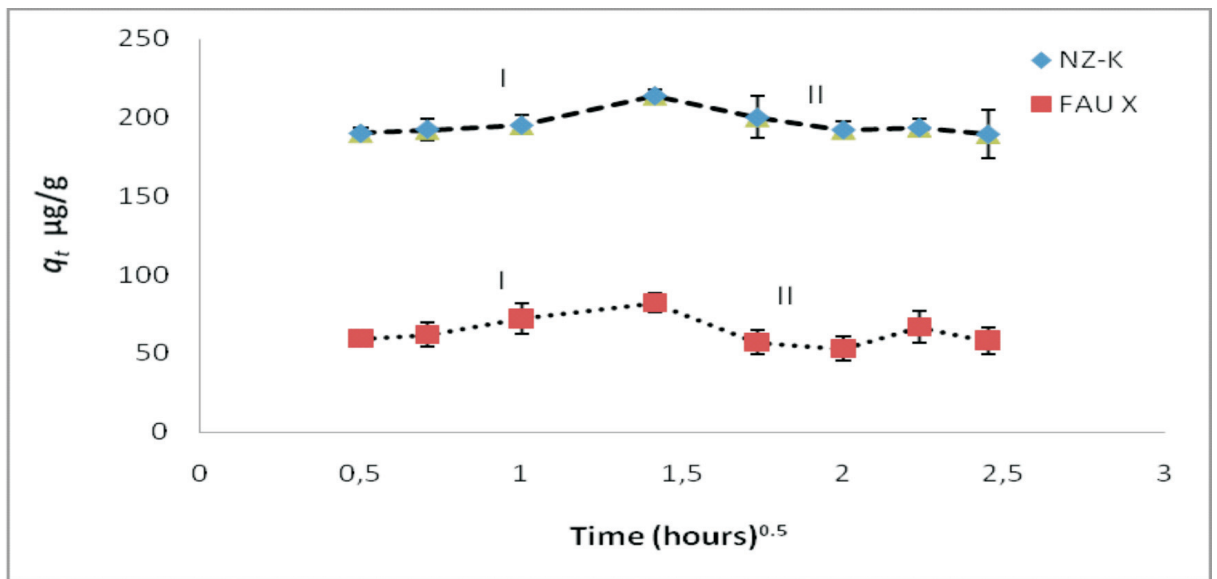

Figure 5 Intraparticle diffusion model graph for clomazone adsorption onto FAU-X and NZ-K (triplicate).

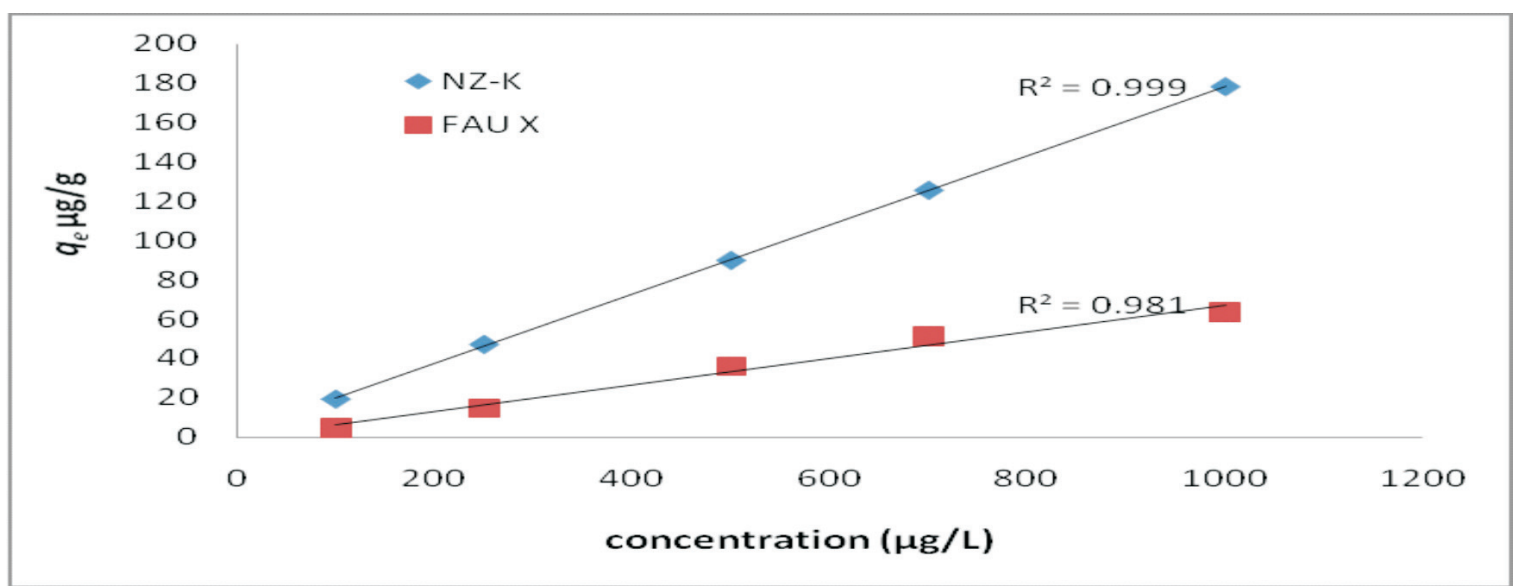

Figure 6 Variation of amount of clomazone adsorbed onto NZ-K and FAU-X as function of initial concentration (triplicate). 
molecules from the solution to the zeolite surface due to increased mass gradient.

The adsorption process was evaluated by fitting the data to three adsorption isotherms; the Langmuir, Freundlich and Temkin isotherms. The calculated isotherm parameters and regression coefficients are listed in Table 3 . Both the Langmuir and Freundlich isotherm models equally best fitted the experimental sorption data with $R^{2}$ closest to unity for both the adsorbents. The conformity to both Langmuir and Freundlich models is a testament of the heterogeneous nature of the zeolite surfaces and supports the earlier suggested multi-linear nature of clomazone adsorption process.

The Langmuir monolayer $\left(Q_{m}\right)$ maximum capacity parameter $\left(500 \mu \mathrm{g} \mathrm{g}^{-1}\right)$ suggests that clomazone may have attained the saturation point of the active binding sites and any further reactions could only take place on new energetically unfavourable surfaces. This phenomenon was earlier exhibited by the maximum adsorption and equilibrium attainment within $2 \mathrm{~h}$ (Fig. 4). Both the Langmuir separation constant $\left(R_{L}=0.3675\right)$ and Freundlich constant $(n=1.1416)$ indicate that the sorption process is favourable for the natural zeolite. The value of $1 / n$ is between 0 and 1 and confirms the hitherto reported heterogeneous nature of zeolite surfaces ${ }^{24,30}$. However, clomazone adsorption onto synthetic FAU-X was unfavourable. Moreover, the negative values of the Langmuir isotherm constants $\left(Q_{m}\right.$ and $\left.K_{L}\right)$ depict the inadequacy of the implicit assumptions of this model to explain clomazone adsorption process onto FAU-X. Similar phenomenon was reported for removal of boron by adsorption

Table 3 Experimentally obtained adsorption isotherm equations parameters (triplicate).

\begin{tabular}{lll}
\hline Isotherm model & $\begin{array}{l}\text { Calculated parameters } \\
\text { for NZ-K }\end{array}$ & $\begin{array}{l}\text { Calculated parameters } \\
\text { for FAU-X }\end{array}$ \\
\hline Langmuir & $\begin{array}{l}Q_{m}\left(\mu \mathrm{g} \mathrm{g}^{-1}\right)=500 \\
K_{L}\left(\mathrm{~L} \mathrm{~g}^{-1}\right)=0.0017\end{array}$ & $\begin{array}{l}Q_{m}\left(\mu \mathrm{g} \mathrm{g}^{-1}\right)=-58.82 \\
K_{L}\left(\mathrm{~L} \mathrm{~g}^{-1}\right)=-8.0410^{-4}\end{array}$ \\
& $R_{L}=0.3675$ & \\
& $R^{2}=0.999$ & \\
Freundlich & $K_{f}=1.2246$ & $K_{f}=4.168 \times 10^{-3}$ \\
& $n=1.1416$ & $n=0.6901$ \\
& $R^{2}=0.999$ & $R^{2}=0.977$ \\
Temkin & $B=-1.366$ & $B=66.14$ \\
& $A_{T}=1.97 \times 10^{-7}$ & $A_{T}=0.132$ \\
& $R^{2}=0.949$ & $R^{2}=0.946$ \\
\hline
\end{tabular}

on $\mathrm{Al}_{2} \mathrm{O}_{3}$ based materials ${ }^{31}$ and also for adsorption of phenol onto activated carbon ${ }^{32}$. The unfavourable adsorption onto FAU-X was attributed to the structural limitations of clomazone as discussed below.

\subsection{Site and Mechanism of Adsorption}

The site and mechanism of adsorption studies were limited to FAU-X because X-ray diffraction (XRD) and Infrared (IR) studies for FAU-X are well documented while for NZ-K is yet to be documented. X-Ray Diffraction analysis was performed to monitor cationic migrations from the FAU-X framework. Such migrations indicate participation of the $\mathrm{Na}^{+}$ions in the adsorption process. In sodium-type faujasite $X$, cationic migrations are characterized by intensity changes for $9.9^{\circ}(2 \theta)$ and $11.6^{\circ}(2 \theta)$ diffractograms ${ }^{26}$. XRD analysis of FAU-X exposed to clomazone; Fau cloma 5-45 (Fig. 7) indicated changes on the relative intensities of the diffractogram at $9.9^{\circ}(2 \theta)$ from 1238.055 to 1345.988 a.u and the diffractogram at $11.6^{\circ}(2 \theta)$ from 2575.391 to 2307.855 a.u. The diffractograms for FAU-X with clomazone were right shifted by $0.6^{\circ}(2 \theta)$ for clarity.

These changes suggest that the cations participate in the adsorption process consistent with chemisorption mechanism. Such subtle changes in the XRD intensities, which depict species movements, have recently been noted by Romero et al. ${ }^{33}$. Thus the cations possibly act as point charges that attract the chlorine atoms in clomazone molecule (Fig. 1). Such changes are consistent with the adsorbate somewhat interacting with inner parts of the zeolite framework, a phenomenon consistent with earlier assertion that intraparticle diffusion is not the only rate determining step. The position of the chlorine atom on the substituted benzene ring of clomazone seems also to influence the low extent of adsorption observed. This may be attributed to the ortho position of chlorine atom in clomazone hence difficult accessibility to the positive charges on the FAU-X rendering steric hindrance to the binding site and increased repulsion between adsorbed molecules as well. This is in contrast to the high adsorption of tebuconazole by FAU-X via cation-chlorine interactions where the chlorine atom is in the para position?. Therefore, the presence of several active cations in NZ-K could explain its high adsorption property.

In the FT-IR spectrum of free faujasite $X$, particularly worth considering were the band around $760 \pm 2 \mathrm{~cm}^{-1}$ resulting from the FAU-X single-four-ring (S4R) vibrations ${ }^{26}$. The FAU-X exposed to clomazone showed a red shift of the S4R from ca. $756 \mathrm{~cm}^{-1}$ to $\mathrm{ca} .742 \mathrm{~cm}^{-1}$ (Fig. 8) confirming that clomazone

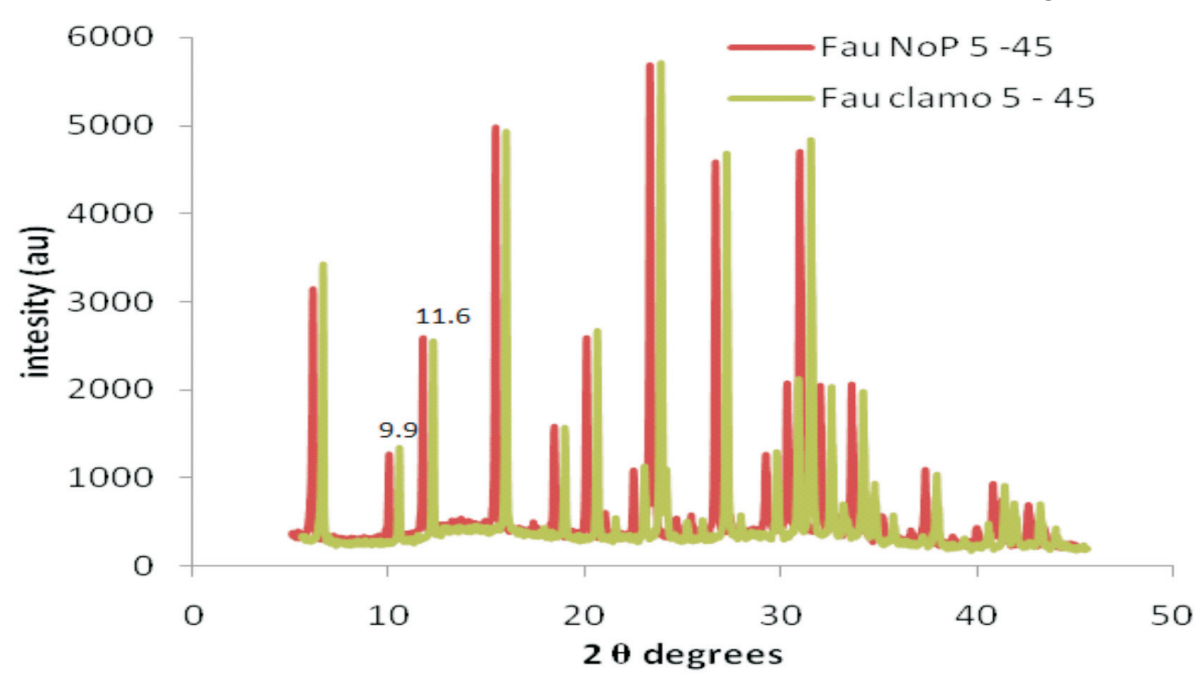

Figure 7 The XRD spectra for FAU-X in clomazone where Fau NoP = FAU-X without pesticide, Fau cloma = FAU-X with clomazone (duplicate). 


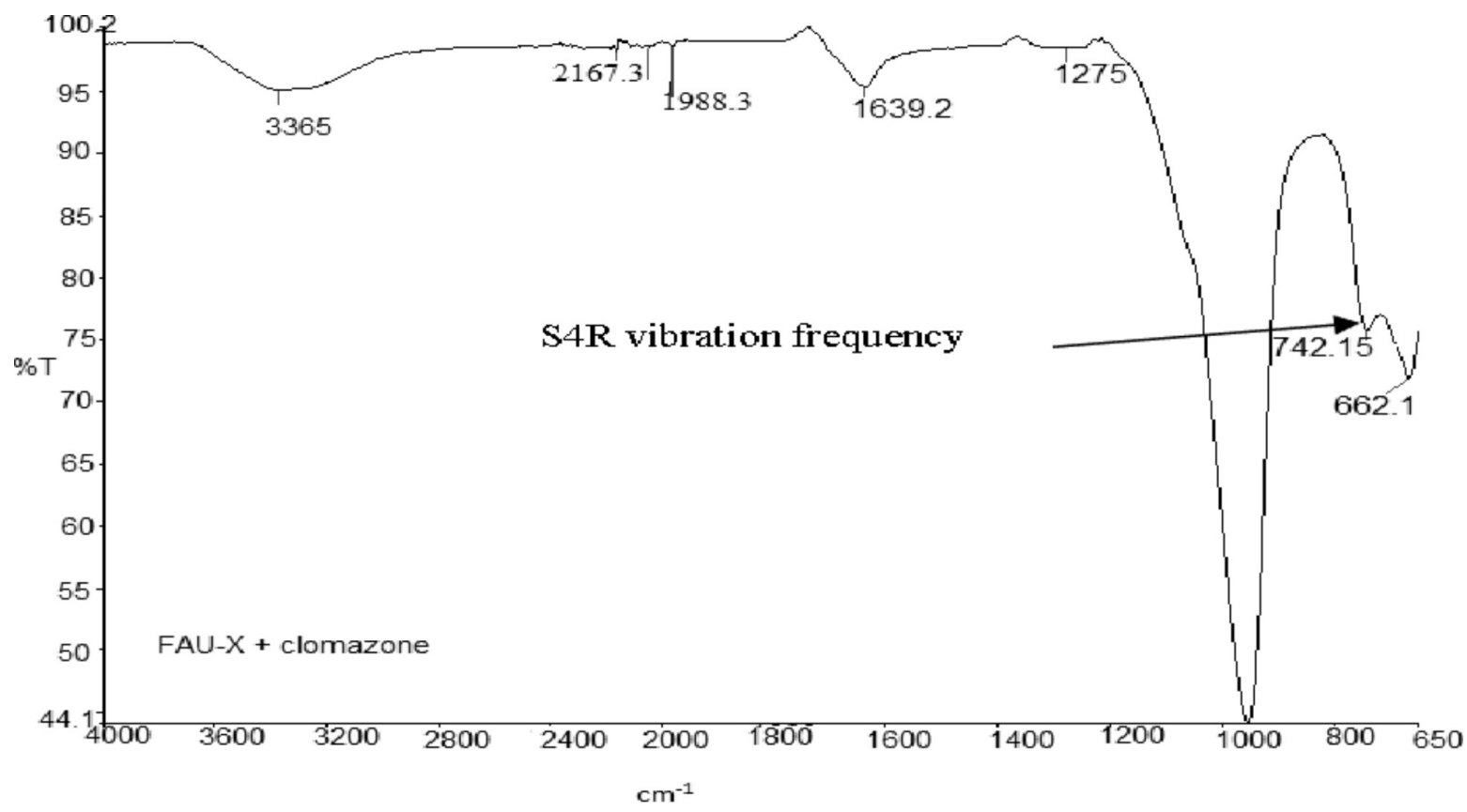

Figure 8 FT-IR spectra of FAU-X with clomazone.

molecules were adsorbed at the single-four-rings of the zeolite framework. These results strongly suggest that clomazone molecules did not reptate much into the internal cavities of the zeolite framework but were mostly adsorbed at the heterogeneous FAU-X surfaces. This observation is consistent with the adsorption isotherms fitting into both Langmuir and Freundlich models. This implication of surface effects by FT-IR in combination with the not wholly a surface effect by XRD support the intraparticle diffusion graph that concluded pore diffusion was not the sole mechanism of the adsoption processs.

\subsection{Adsorption Thermodynamics}

The effect of temperature changes on the adsorption was studied in the range 293-323 K to determine the relative thermodynamic feasibility of the adsorption process onto the two zeolites. As the temperature was varied from $293 \mathrm{~K}$ to $323 \mathrm{~K}$, the percentage removal of clomazone by natural zeolite decreased from 71.3 to $59.8 \%$ (Table 4 ) and by half from 12.9 to $6.5 \%$ for FAU-X, an indication of an exothermic process. This percentage decrease in removal efficiency is attributable to the concomitant weakening of binding forces between the zeolite framework and clomazone molecules and increased clomazone solubility in the water when the temperature rises thus lowering the molecules' affinity for the adsorbent surface ${ }^{34}$. This decrease also confirms that the adsorption process is not only controlled by the intraparticle transport-pore diffusion as earlier inferred. It is worthy to note that, the pesticide removal efficiency by the natural zeolite for clomazone is at least five-fold superior to FAU-X.

The thermodynamic parameter $\Delta \mathrm{G}$ (Table 4) was estimated using the following equations ${ }^{35}$ :

$$
\begin{aligned}
& \Delta G=-R T \ln K_{c} \\
& K_{c}=\frac{C_{a d}}{C_{e}}
\end{aligned}
$$

where $K_{c}$ is the equilibrium constant, $C_{e}$ is the equilibrium concentration in the solution $\left(\mu \mathrm{g} \mathrm{L}^{-1}\right)$ and $C_{a d}$ is the equilibrium solid phase concentration $\left(\mu \mathrm{g} \mathrm{L}^{-1}\right)$. The changes in enthalpy $(\Delta \mathrm{H})$ and entropy $(\Delta S)$ were obtained from slope and intercept of the Van't Hoff plot, respectively.

$$
\ln K_{c}=\frac{\Delta S}{R}-\frac{\Delta H}{2.303 R} \frac{1}{T}
$$

Thermodynamically, spontaneous and non-spontaneous processes are indicated by negative and positive $\Delta \mathrm{G}$ changes, respectively. Therefore, the $\Delta \mathrm{G}$ values confirm that clomazone adsorption onto the natural zeolite is spontaneous but nonspontaneous for FAU-X though exothermic for both adsorbents. However, the magnitudes of $\Delta \mathrm{H}$ and $\Delta \mathrm{S}$ (Table 4) indicate that the adsorption of clomazone onto FAU-X is entropically driven and that the system, therefore, draws energy from its surrounding. Sapawe et al. ${ }^{36}$ and Laifu et al. ${ }^{37}$ had earlier experienced similar findings. Generally, the magnitude of $\Delta \mathrm{H}$ value ranges from $40-120 \mathrm{~kJ} \mathrm{~mol}^{-1}$ for chemisorption mechanisms ${ }^{36}$. In the

Table 4 Thermodynamic parameters for removal of clomazone by FAU-X and NZ-K (triplicate).

\begin{tabular}{cccccc}
\hline Zeolite & $\begin{array}{c}\text { Temperature } \\
\text { /K }\end{array}$ & \% Removal & $\begin{array}{c}\Delta \mathrm{G} \\
/ \mathrm{J} \mathrm{mol}^{-1}\end{array}$ & $\begin{array}{c}\Delta \mathrm{H} \\
/ \mathrm{kJ} \mathrm{mol}^{-1}\end{array}$ & $\begin{array}{c}\Delta \mathrm{S} \\
/ \mathrm{Jmol}^{-1} \mathrm{~K}^{-1}\end{array}$ \\
\hline \multirow{2}{*}{ NZ-K } & 293 & 71.3 & -2221.1 & -28.6 & -35.5 \\
& 303 & 62.7 & -1306.4 & & \\
& 313 & 61.5 & -1293.8 & & -82.7 \\
\\
& 323 & 59.8 & -1071.2 & & \\
\\
\end{tabular}


present investigation, the $\Delta \mathrm{H}$ values indicate a physisorption $\left(-28.6 \mathrm{~kJ} \mathrm{~mol}^{-1}\right)$ and chemisorptions $\left(-44.9 \mathrm{~kJ} \mathrm{~mol}^{-1}\right)$ process for the natural and synthetic zeolite, respectively. The negative $\Delta S$ value implies less randomness at the solid/solution interfaces, consistent with an adsorption process of clomazone onto both NZ-K and FAU-X has indeed taken place.

\section{Conclusion}

This work established that the natural zeolite from Kenya (NZ-K) is an efficient adsorbent for removal of clomazone from aqueous solution, approximately five-fold superior to synthetic faujasite $\mathrm{X}$ zeolite (FAU-X). The equilibrium sorption data were well represented by both Langmuir and Freundlich models indicating a multi-mechanistic adsorption process. The adsorption processes were found to follow pseudo-second-order kinetics with a pseudo-equilibrium time of $2 \mathrm{~h}$. The thermodynamic calculations indicated that the adsorption process is feasible, spontaneous and exothermic for the NZ-K and non-spontaneous for FAU-X via a physical and chemical process, respectively. From the findings, the natural zeolite can be an efficient and cost-effective alternative adsorbent for clomazone removal from aquatic ecosystems.

\section{Acknowledgements}

The authors are grateful to exceed partnership program (www.exceed.tu-braunschweig.de) for the award of student exchange study scholarship to the first author and the collaboration between the two institutions involved.

\section{References}

1 R. Zanella, E.G. Primel, S.L.O. Machado, F.F. Goncealves and E. Marchezan, Monitoring of the herbicide clomazone in environmental water samples by solid-phase extraction and highperformance liquid chromatography with ultraviolet detection. Chromatogr., 2002, 55, 573-577.

2 J.D. Mattice, B.W. Skulman, R.J. Norman and E.E. Gbur, Analysis of river water for rice pesticides in eastern Arkansas from 2002 to 2008 J. Soil. Water. Conserv., 2010, 65, 130-140.

3 M. Crestani, C. Menezes, L. Glusczak, D. Miron, R. Spanevello, A. Silveira, G. Ferreira, R. Zanella and V. Loro, Effect of clomazone herbicide on biochemical and histological aspects of silver catfish (Rhamdia quelen) and recovery pattern. Chemosphere, 2007, 67, 2305-2311.

4 D. Miron, M. Crestani, M.R. Schetinger, V.M. Morsch, B. Baldisserotto, M.A. Tierno, G. Moraes and V.L.P. Vieira, Effects of the herbicides clomazone, quinclorac and metsulfuron methyl on acetylcholinesterase activity in the silver catfish (Rhamdia quelen) (Heptapteridae). Ecotoxicol. Environ. Saf., 2005, 61, 398-403.

5 P.E. Stackelberg, J. Gibs, E.T. Furlong, T.M. Michael, S.D. Zaugg and L. Lippincott, Efficiency of conventional drinking-water-treatment processes in removal of pharmaceuticals and other organic compounds. Sci. Total Environ., 2007, 377, 255-272.

6 B.F. Abramovic, V.N. Despotovic, D.V. Šojic, Z.O. Dejan J. János and D. Dragana Photocatalytic degradation of the herbicide clomazone in natural water using $\mathrm{TiO}_{2}$ : kinetics, mechanism and toxicity of degradation products. Chemosphere, 2013, 93, 166-171.

7 S. Chiron, L. Comoretto, E. Rinaldi, V. Maurino, C. Mireno and D. Vione, Pesticide by-products in the Rhone delta (southern France). The case of 4-chloro-2-methylphenol and of its nitroderivative. Chemosphere, 2009, 74, 599-604.

8 C.O. Kowenje, E.T. Osewe and J.O. Lalah, Effects of faujasite X and $Y$ zeolites on the 1,1,1-trichloro-2,2' bis(p-chlorophenyl)ethane (DDT) degradation during water purification. Int. J. Environ. Prot. Policy, 2013, 1, 9-15.

9 V.O. Shikuku, C.O. Kowenje, M.K. Ongeri, R. Zanella and O.D. Prestes, Removal of tebuconazole from wastewater by zeolite $X$ kinetics and thermodynamics studies. Int. J. Eng. Res. Technol., 2014, 3(8), 1584-1590.

10 S. Wang and Y. Peng, Natural zeolites as effective adsorbents in water and wastewater treatment. Chem. Eng. J., 2010, 156, 11-24.
11 P.P. Diale, E. Muzenda, M. Iaeng and J. Zimba, A study of South African natural zeolites properties and applications. Proc. World Congress Eng. Comput. Sci., 2011, Vol II, October 19-21, 2011, San Francisco, USA.

12 E. Alver and U. Metin, Anionic dye removal from aqueous solutions using modified zeolite: adsorption kinetics and isotherm studies. Chem. Eng. J., 2012, 200-202, 59-67.

13 Y.S. Ho, Citation review of Lagergren kinetic rate equation on adsorption reactions. Scientom., 2004, 59, 171-177.

14 Y.S. Ho, Review of second-order models for adsorption systems. J. Hazard. Mater., 2006, 136, 681-689.

15 W.J. Weber and J.C. Morris, Kinetics of adsorption on carbon from solution. J. San. Eng.: Am. Soc. Civ. Eng., 1963, 89, 31-59.

16 I. Langmuir, The adsorption of gases on plane surface of glass, mica and platinum. J. Am. Chem. Soc. 1918, 40, 1361-1403.

17 H. Freundlich, Over the adsorption in solution. J. Phys. Chem., 1906, $57,385-470$.

18 M.J. Temkin and V. Pyzhev, Recent modifications to Langmuir isotherms. Acta Physiochim., 1940, 12, 217-222.

19 G. Moussavi, H. Hosseini and A. Alahabadi, The investigation of diazinon pesticide removal from contaminated water by adsorption onto $\mathrm{NH}_{4} \mathrm{Cl}$-induced activated carbon. Chem. Eng. J., 2013, 214, 172-179.

20 Commission on natural zeolites (CNZ), 2015. http://www.iza-online.org/natural/Datasheets/Phillipsite/phillipsite.htm, accessed on 5 September 2015.

21 M.M. Hussein, K.M. Khader and S.M. Musleh, Characterization of raw zeolite and surfactant-modified zeolite and their use in removal of selected organic pollutants from water. Int. J. Chem. Sci., 2014, 12(3), 815-844.

22 N. Mansouri, N. Rikhtegar, H.A. Panahi, F. Atabi and B.K. Shahraki, Porosity, Characterization and structural properties of natural zeolite - clinoptilolite - as a sorbent. Environ. Prot. Eng., 2013,39(1),139-153.

23 S. Afsaneh, G. Rafael, K. Frank-Dieter, Z. Pezhman and G. Anett, Natural and synthetic zeolites in adsorption/oxidation processes to remove surfactant molecules from water. Sep. Purif. Technol., 2014, 127, 1-9.

24 Y.S. Ho and G. McKay, Kinetic models for the sorption of dye from aqueous solution by wood. Process Saf. Environ. Prot., 1998, 76, 183-191.

25 M.S. Bilgili, Adsorption of 4-chlorophenol from aqueous solutions by xad-4 resin: isotherm, kinetic and thermodynamic analysis. J. Hazard. Mater., 2006, 137, 157-164.

26 C.O. Kowenje, B.R. Jones, D.C. Doetschman, S.W. Yang, J. Schulte, J. De Coste and C.W. Kanyi, Effects of copper exchange levels on complexation of ammonia in $\mathrm{Cu}$ (II)-exchanged $\mathrm{X}$ zeolites. S. Afr. J. Chem., 2010, 63, 6-10.

27 D.K. Mahmoud, M.A.M. Salleha, W.A. Karim, A. Idris and Z.Z. Abidin, Batch adsorption of basic dye using acid treated kenaf fibre char: equilibrium, kinetic and thermodynamic studies. Chem. Eng. J., 2012, 181-182, 449-457.

28 M. Kousha, E. Daneshvar, M.S. Sohrabi, M. Jokar and A. Bhatnagar, Adsorption of acid orange II dye by raw and chemically modified brown macroalga Stoechospermum marginatum. Chem. Eng. J., 2012, 192, 67-76.

29 A.A. Jalil, S. Triwahyono, M.R. Yaakob, Z.A. Azmi, N. Sapawe, N.N. Kamarudin, H.D. Setiabudi, N.F. Jaafar, S.M. Sidik, S.H. Adam and B.H. Hameed Utilization of bivalve shell-treated Zea mays L. (maize) husk leaf as a low-cost biosorbent for enhanced adsorption of malachite green. Bioresour. Technol., 2012, 120, 218-224.

30 K.R. Hall, L.C. Eagleton, A. Acrivos and T. Vermeulen, Pore- and solid-diffusion kinetics in fixed-bed adsorption under constantpattern conditions. Ind. Eng. Chem. Fundam., 1966, 5, 212-223.

31 Y. Seki, S. Serap and Y. Muruvvet, Removal of boron from aqueous solution by adsorption on $\mathrm{Al}_{2} \mathrm{O}_{3}$ based materials using full factorial design. J. Hazard. Mater., 2006, 138, 60-66.

32 H.I. Maarof and B.H. Hameed Adsorption isotherms for phenol onto activated carbon. Arab. J. Chem., 2004, 4, 70-76.

33 D. Romero, D. Chlala, M. Labaki, S. Royer, J. Bellat, I. Bezverkhyy, J. Giraudon and J. Lamonier, Removal of toluene over NaX zeolite exchanged with $\mathrm{Cu}^{2+}$. Catalysts, 2015, 5, 1479-1497.

34 N. Daneshvar, S. Aber, A. Khani and A.R. Khataee, Study of 
S. Afr. J. Chem., 2015, 68, 245-252,

$<$ http://journals.sabinet.co.za/sajchem/>.

imidacloropide removal from aqueous solution by adsorption onto granular activated carbon using an on-line spectrophotometric analysis system. J. Hazard. Mater., 2007, 144, 47-51.

35 M. Ahmaruzzaman and S.G. Laxmi, Batch adsorption of 4-nitrophenol by acid activated jute stick char: equilibrium, kinetic and thermodynamic studies. Chem. Eng. J., 2010, 158, 173-180.

36 N. Sapawe, A.A, Jalil, S. Triwahyono, M. Shah, R. Jusoh, N.F.M. Salleh, B.H. Hameed and A.H. Karim, Cost-effective microwave rapid synthesis of zeolite NaA for removal of methylene blue. Chem. Eng. J., 2013, 229, 388-398.

37 L. Laifu, G. Manglai, G. Zheng, Y. Senfeng and L. Yuening, A comparative study and evaluation of sulfamethoxazole adsorption onto organo-montmorillonites. J. Environ. Sci., 2014, 26, 2535-2545.

38 M. Alkan D. Ozcan, C. Sermet and D. Mehmet, Sorption of acid red 57 from aqueous solution onto sepiolite. J. Hazard. Mater., 2004, 116, $135-145$. 